\title{
VIABILIDADE DA PRODUÇÃO E SIMULAÇÃO DA SECAGEM DO MALTE DE MILHO
}

\author{
R. BAILLY ${ }^{1}$, S. C. da SILVA FILHO ${ }^{2}$; N. M. N. SATO²; J. B. SEVERO JÚNIOR ${ }^{3}$; R. R. de \\ SOUZA $^{3}$; J. C. C. SANTANA ${ }^{1}$ \\ ${ }^{1}$ Universidade Nove de Julho, Programa de Pós-Graduação em Engenharia de Produção \\ ${ }^{2}$ Universidade Nove de Julho, Departamento de Ciências Exatas \\ ${ }^{3}$ Universidade Federal de Sergipe, Departamento de Engenharia Química \\ E-mail: jccurvelo@yahoo.com.br
}

\begin{abstract}
RESUMO - Este trabalho objetivou a simulação da secagem do malte de milho em um secador de ondas infravermelhas, bem como a produção e a análise das qualidades sensoriais da cerveja obtida a partir deste malte. Alguns modelos de secagem foram usados para simular as isotermas de secagem em 41, 45, 55, 65 e $69{ }^{\circ} \mathrm{C}$. Duas cervejas foram preparadas a partir do malte de milho foram obtidas e suas qualidades foram comparadas com duas cervejas tradicionais de cevada. O custo de produção destas cervejas foi comparado para verificar a viabilidade econômica do processo. Os resultados mostraram que a melhor condição para a secagem do malte milho foi a $55^{\circ} \mathrm{C}$ por $1,5 \mathrm{~h}$ de processo, e este tempo foi de cerca de 4 vezes menor do que a secagem em um secador convectivo. Comparando a qualidade sensorial da cerveja de milho mostrou que ela foi tão boa quanto às cervejas comerciais, além do seu custo ser $12 \%$ menor, o que torna este processo viável e competitivo.
\end{abstract}

\section{INTRODUÇÃO}

A secagem é um processo de remoção de uma substância volátil (comumente, mas não exclusivamente, a água) de um produto sólido, ou seja, é a operação pela qual a atividade de água de um determinado produto é diminuída, por meio de sua vaporização, e a água presente no sólido é chamada de umidade (Jesus, 2002). De acordo com Resende et al. (2008), a secagem é um dos processos mais usados na preparação de produtos agrícolas, pois assegura a sua qualidade e estabilidade. Já que a diminuição da quantidade de água do material reduz a atividade biológica e, conseqüentemente, reduz as alterações químicas e físicas que ocorrem durante o armazenamento.

Para se conhecer o comportamento da retirada da umidade do produto, é necessário se obter as curvas de secagem experimentalmente ou via modelos de secagem, como os citados em alguns trabalhos. Por exemplo: Phoungchandang et al. (2008) utilizaram um secador de bandejas para a desidratação das folhas de amoreira branca. Dentre os modelos testados, o que mais se ajustou foi o proposto por Henderson et al. (1968). Em seu trabalho, Ceylan (2008) efetuou a secagem de toras de pinheiros utilizando o secador de calor convectivo operando $24 \mathrm{~h}$ por dia, e seus dados 
foram testados em modelos de secagem convencionais, inseridos no computador para facilitar a simulação do processo. A alteração de peso em todas as madeiras foi seguida na câmara de secagem, que foi interrompida quando o peso desejado foi alcançado. Omid et al. (2008) simularam com êxito a secagem de pistache utilizando um secador de camada delgada, com quatro velocidades de fluxo de ar de entrada e com cinco temperaturas de secagem variando entre 40 e $80^{\circ} \mathrm{C}$.

Assim, este trabalho objetivou a simulação da secagem do malte de milho em um secador de ondas infravermelhas, bem como a produção e a análise das qualidades sensoriais da cerveja obtida a partir deste malte para agregar valor a cultura do milho.

\section{MATERIAL E MÉTODOS}

\subsection{Obtenção das da Curva de Secagem}

A secagem foi realizada em um secador infravermelho a 41, 45, 55, 65 e $69^{\circ} \mathrm{C}$ e em um secador convectivo com circulação de ar, para a comparação entre as técnicas. Estas temperaturas foram escolhidas por estarem próximas das temperaturas ótimas das enzimas amilases. As sementes maltadas foram postas em vidro de relógio, previamente secos nas devidas temperaturas. Então, foram medidas as suas massas iniciais $\left(\boldsymbol{X}_{\boldsymbol{0}}\right)$, úmidas, e postas para secar nas temperaturas indicadas. De tempo em tempo, as amostras foram coletadas e medidas as suas massas $\left(\boldsymbol{X}_{\boldsymbol{i}}\right)$ no tempo específico de secagem. O conteúdo de umidade retirada $\left(\boldsymbol{M}_{\boldsymbol{i}}\right)$ do malte e a variação da massa com o tempo $(\boldsymbol{X})$, na forma adimensional, foram calculados pelo uso das Equações 1 e 2, respectivamente. As isotermas de sorção foram montadas a partir da variação da massa seca adimensional versus o tempo de secagem nas temperaturas de $41,45,55,65$ e $69^{\circ} \mathrm{C}$ (Biazus et al., 2005 e 2006; Santana et al., 2010).

$$
\begin{aligned}
& M_{i}=\left(\frac{X_{0}-X_{i}}{X_{0}}\right) * 100 \\
& X=\frac{X_{i}}{X_{0}}
\end{aligned}
$$

Duas cervejas de malte de milho foram preparadas, um com o fermento Flashmann ${ }^{\circledR}$ (A) e Fermix ${ }^{\circledR}(\mathrm{C})$ como fonte de $S$. cerevisae durante a fermentação. Estas cervejas foram comparadas sensorialmente por 30 degustadores com duas (B e D) cervejas comerciais, que avaliaram o sabor, o aroma e a aparência em uma escala hedônica de 1-9.

\subsection{Modelos De Secagem}

Os modelos testados foram baseados nos modelos matemáticos, empíricos e semiempíricos, apresentados na Tabela 1, como propostos por Barrozo et al. (1994) e Guedes e Farias (2000). Os parâmetros a serem determinados são: a constante cinética de secagem, $\boldsymbol{K}\left(\mathrm{min}^{-1}\right)$ e as constantes $\boldsymbol{A}$ e $\boldsymbol{B}$, derivadas da equação de Arrhenius. A avaliação do ajuste dos modelos 
empíricos foi feita tomando-se como base a metodologia de análise da variância (ANOVA) descrita por Barros Neto et al. (2007).

Tabela 1. Modelos empíricos e semi-empíricos para descrever as isotermas de secagem.

\begin{tabular}{ccc}
\hline Equação & Referência & Equação Padrão \\
\hline $\mathbf{3}$ & Brooker et al. (1974) & $X=A \cdot e^{-k t}$ \\
$\mathbf{4}$ & Lewis (1921) & $X=e^{-k t}$ \\
$\mathbf{5}$ & Thompson et al.(1968) & $t=A \ln X+B(\ln X)^{2}$ \\
$\mathbf{7}$ & Wang \& Singh.(1978) & $X=1+A t+B t^{2}$ \\
\hline
\end{tabular}

Fontes: Barrozo et al. (1994) e Guedes e Farias (2000)

\subsection{Montagem Do Simulador}

Um simulador foi construído utilizando a linguagem de programação Java JVM, Tomcat (servidor de aplicações), com banco de dados HDBSQL, devido ao seu custo, pois como são ferramentas consideradas de código aberto, estão disponíveis no mercado de forma gratuita. O equipamento utilizado para a criação deste simulador foi um monitor de 20 polegadas LCD, 1600x900, com as seguintes características: Processador Core i3 3220, RAM de 4GB, HD de 500GB, memória de $3 \mathrm{MB}$. O algoritmo foi montado de forma a receber as equações da Tabela 1 , utilizadas nas simulações das curvas de secagem. Em seguida, foram inseridos (pela digitação) os dados coletados para $\boldsymbol{t}$ e $\boldsymbol{X}$ (apresentados na Tabela 2) para cada temperatura de secagem. Em princípio, o simulador armazena dados em sua memória e gera resultados, com 4 casas decimais (precisão da balança = 0,0001). Finalizado o processo de obtenção dos dados, o simulador iniciou o processo de identificação de qual é o melhor modelo a ser utilizado, baseado na comparação dos valores da correlação $(\boldsymbol{R})$ obtida para cada modelo. Os modelos que atingirem uma correlação próxima da unidade foram considerados como os mais ajustados (Barros Neto et al., 2007). O simulador, após a escolha do melhor modelo, gerou os gráficos que representam as curvas de secagem em LIB Jexcel (biblioteca do Java para utilizar gráficos do Excel), para cada temperatura.

\section{RESULTADOS E DISCUSSÕES}

A Tabela 2 apresenta os resultados experimentais obtidos durante a secagem do malte de milho no secador infravermelho. Nota-se que para $69^{\circ} \mathrm{C}$ a estabilidade da massa seca começa a ser notada após os $120 \mathrm{~min}$, com uma retirada de aproximadamente 48,5\% da umidade, já para a temperatura de $40^{\circ} \mathrm{C}$ a estabilidade começa a ser notada após os $240 \mathrm{~min}$, com uma retirada de $40 \%$ de umidade. No entanto, percebe-se que a $55^{\circ} \mathrm{C}$ a retirada de umidade chega aos $46 \%$, em média, aos 90 min de processo. Indicando esta temperatura como sendo a melhor, para o processo, já que há um gasto baixo energia com um tempo reduzido de processo. Observou-se também que para a temperatura de $69^{\circ} \mathrm{C}$, no tempo de processo de 100 min a quantidade de umidade retirada está próxima da alcançada pelos $50^{\circ} \mathrm{C}$ a $90 \mathrm{~min}$, o que pode indicar que a 


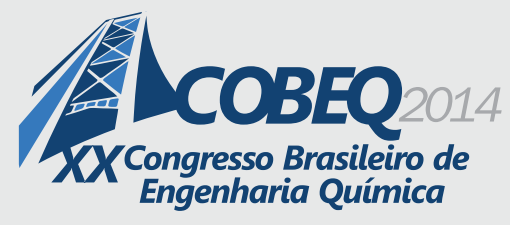

19 a 22 de outubro de 2014
Florianópolis/SC

secagem a $69^{\circ} \mathrm{C}$ deva estar se prolongando até a retirada da umidade de ligação, o que ficou caracterizado pelo escurecimento e até a "queima” da casca das sementes.

Biazus et al. (2006) e Santana et al., (2010) determinaram que a secagem do malte de milho deve ser feita a $55^{\circ} \mathrm{C}$, em um secador convectivo com circulação de ar (convencional), pois nestas condições, a atividade enzimática do malte seco foi 5,26 vezes maior do que a atividade inicial do malte, 20 mil vezes maior do que a atividade do milho "in natura" e 1,5 vezes maior do que a atividade do malte de cevada. De acordo com Biazus et al. (2006), este malte seco pode ser conservado por até 19 semanas, tanto na temperatura ambiente como resfriado a $10^{\circ} \mathrm{C}$, assim, o produto pode ser estocado por um longo período sem ser contaminado por microorganismos e sem perder a sua qualidade.e no secador projetado neste trabalho, com luz infravermelha. Estes dois experimentos foram necessários para que se pudessem comparar as duas técnicas de secagem. Entretanto, o tempo ideal para a secagem ficou entre 5,18 e 6 h (311 e 360 minutos), já que somente após estas condições o malte estava seco, perdendo até $43 \%$ de umidade.

Tabela 2. Dados experimentais da secagem do malte de milho usando o secador infravermelho

\begin{tabular}{|c|c|c|c|c|c|c|c|c|c|}
\hline \multicolumn{2}{|c|}{$41^{\circ} \mathrm{C}$} & \multicolumn{2}{|c|}{$45^{\circ} \mathrm{C}$} & \multicolumn{2}{|c|}{$55^{\circ} \mathrm{C}$} & \multicolumn{2}{|c|}{$65^{\circ} \mathrm{C}$} & \multicolumn{2}{|c|}{$69^{\circ} \mathrm{C}$} \\
\hline$t(\mathrm{~min})$ & $\mathrm{X}(\mathrm{g} / \mathrm{g})$ & $t(\min )$ & $\mathrm{X}(\mathrm{g} / \mathrm{g})$ & $t(\min )$ & $\mathrm{X}(\mathrm{g} / \mathrm{g})$ & $t(\min )$ & $\mathrm{X}(\mathrm{g} / \mathrm{g})$ & $t$ (min) & $X(g / g)$ \\
\hline 0 & 1,0000 & 0 & 1,0000 & 0 & 1,0000 & 0 & 1,0000 & 0 & 1,0000 \\
\hline 20 & 0,8100 & 20 & 0,8858 & 15 & 0,7991 & 15 & 0,8507 & 20 & 0,8089 \\
\hline 40 & 0,7924 & 40 & 0,8409 & 30 & 0,7482 & 30 & 0,7894 & 40 & 0,7031 \\
\hline 60 & 0,7566 & 60 & 0,8080 & 45 & 0,6449 & 45 & 0,7439 & 60 & 0,6555 \\
\hline 90 & 0,7725 & 90 & 0,7782 & 60 & 0,7058 & 60 & 0,6980 & 80 & 0,6271 \\
\hline 120 & 0,7120 & 120 & 0,7552 & 75 & 0,6480 & 75 & 0,6669 & 100 & 0,5898 \\
\hline 150 & 0,7131 & 150 & 0,7311 & 90 & 0,5627 & 90 & 0,6434 & 120 & 0,5209 \\
\hline 180 & 0,6697 & 180 & 0,7098 & 105 & 0,5433 & 105 & 0,6718 & 140 & 0,5396 \\
\hline 210 & 0,6774 & 200 & 0,7140 & 120 & 0,5920 & 120 & 0,6396 & 160 & 0,5159 \\
\hline 240 & 0,6120 & 220 & 0,6947 & 135 & 0,5218 & 135 & 0,6391 & 180 & 0,5079 \\
\hline 270 & 0,5748 & 240 & 0,6820 & 155 & 0,5512 & 154 & 0,5981 & 210 & 0,5066 \\
\hline 300 & 0,5357 & 270 & 0,6822 & 165 & 0,5325 & 165 & 0,6082 & 235 & 0,4972 \\
\hline 360 & 0,5559 & 300 & 0,6792 & 180 & 0,5047 & 180 & 0,6084 & 260 & 0,5173 \\
\hline 420 & 0,6136 & 360 & 0,6517 & & & 200 & 0,5809 & & \\
\hline \multirow[t]{2}{*}{460} & 0,5538 & 420 & 0,6523 & & & 220 & 0,5882 & & \\
\hline & & 480 & 0,6329 & & & 240 & 0,5906 & & \\
\hline
\end{tabular}

A Tabela 3 apresenta os resultados dos ajustes dos modelos, seus respectivos parâmetros de cinética de secagem e correlação (R). De acordo com Barros Neto et al. (2007), quanto mais próximo de 1,0 estiver o seu coeficiente correlação (R) mais ajustado estará o modelo. Assim, de acordo com os dados apresentados na Tabela 3, pode-se considerar que o modelo de Thompson et al. (1968) é, dentre os modelos estudados neste trabalho, o mais ajustado aos dados experimentais de secagem do malte de milho por ondas infravermelhas, pois todos os seus valores de $\mathrm{R}$ foram superiores a 0,90. 
Tabela 3. Resultados obtidos para o ajuste dos modelos de secagem.

\begin{tabular}{ccc|cc}
\hline Modelo & \multicolumn{2}{c|}{ Brooker et al. (1974); } & \multicolumn{2}{c}{ Lewis (1921) } \\
$\mathrm{T}\left({ }^{\circ} \mathrm{C}\right)$ & $\boldsymbol{X}=\boldsymbol{A} \exp (-\boldsymbol{K} \boldsymbol{t})$ & $\mathrm{R}$ & $\boldsymbol{X}=\exp (-\boldsymbol{K} \boldsymbol{t})$ & $\mathrm{R}$ \\
\hline 41 & $\mathrm{X}=0,8366 \exp (-0,0010) \mathrm{t}$ & 0,8900 & $\mathrm{X}=\exp (-0,0020) \mathrm{t}$ & 0,6375 \\
45 & $\mathrm{X}=0,8613 \exp (-0,0008) \mathrm{t}$ & 0,9003 & $\mathrm{X}=\exp (-0,0010) \mathrm{t}$ & 0,5520 \\
55 & $\mathrm{X}=0,8330 \exp (-0,0030) \mathrm{t}$ & 0,9061 & $\mathrm{X}=\exp (-0,0050) \mathrm{t}$ & 0,7540 \\
65 & $\mathrm{X}=0,8299 \exp (-0,0020) \mathrm{t}$ & 0,8856 & $\mathrm{X}=\exp (-0,0030) \mathrm{t}$ & 0,5740 \\
69 & $\mathrm{X}=0,7931 \exp (-0,0020) \mathrm{t}$ & 0,8712 & $\mathrm{X}=\exp (-0,0040) \mathrm{t}$ & 0,6222 \\
\hline Modelo & \multicolumn{2}{c}{ Thompson et al $(1968)$} & $\mathrm{Wang}$ \& Singh. $(1978)$ \\
$\mathrm{T}\left({ }^{\circ} \mathrm{C}\right)$ & $\boldsymbol{t}=\boldsymbol{A} \ln \boldsymbol{X}+\boldsymbol{B}[\ln \boldsymbol{X}]^{2}$ & $\mathbf{R}$ & $\boldsymbol{X}=1+\boldsymbol{A t}+\boldsymbol{B t}^{2}$ & $\mathrm{R}$ \\
\hline 41 & $\mathrm{t}=-118,6 \ln \mathrm{x}+671,2(\ln \mathrm{x})^{2}$ & $\mathbf{0 , 9 0 2 6}$ & $\mathrm{X}=1-0,0027 \mathrm{t}+2.10^{-6} \mathrm{t}^{2}$ & 0,8744 \\
45 & $\mathrm{t}=453,1 \ln \mathrm{X}+3358(\ln \mathrm{x})^{2}$ & $\mathbf{0 , 9 8 4 7}$ & $\mathrm{X}=1-0,0021 \mathrm{t}+2.10^{-6} \mathrm{t}^{2}$ & 0,8973 \\
55 & $\mathrm{t}=-1,244 \ln \mathrm{X}+360,9(\ln \mathrm{x})^{2}$ & $\mathbf{0 , 9 4 1 6}$ & $\mathrm{X}=1-0,0070 \mathrm{t}+210^{-5} \mathrm{t}^{2}$ & 0,9275 \\
65 & $\mathrm{t}=186,4 \ln \mathrm{x}+1134(\ln \mathrm{x})^{2}$ & $\mathbf{0 , 9 6 2 2}$ & $\mathrm{X}=1-0,0050 \mathrm{t}+1.10^{-5} \mathrm{t}^{2}$ & 0,9184 \\
69 & $\mathrm{t}=97,35 \ln \mathrm{x}+599,3(\ln \mathrm{x})^{2}$ & $\mathbf{0 , 9 2 7 5}$ & $\mathrm{X}=1-0,0058 \mathrm{t}+1.10^{-5} \mathrm{t}^{2}$ & 0,9508 \\
\hline
\end{tabular}

As Figuras 1.a, 1.b, 2.a, 2.b e 3 apresentam as telas geradas pelo simulador para as curvas de secagem do secagem do malte de milho por ondas infravermelhas nas temperaturas 41, 45, 55, 65 e $69^{\circ} \mathrm{C}$, respectivamente. Nestas figuras, também são apresentados os dados experimentais, sob a forma logarítmica e as suas respectivas simulações, realizadas de acordo com o modelo que mais se ajustou aos dados deste experimento. Como se nota, as curvas geradas pelo modelo de Thompson et al. (1968) se aproximam das curvas obtidas pelos dados experimentas, ou seja, o modelo de Thompson consegue prever a retirada da umidade do malte de milho na secagem por ondas infravermelhas. Com isto, pôde-se verificar que o simulador atingiu o seu objetivo, conseguindo mostrar qual, dentre os modelos, é o melhor para simular a secagem de um grão específico, e a partir desta simulação, qual pode contribuir com as empresas de beneficiamento de grãos, já que é possível prever quando o grão específico estará seco.

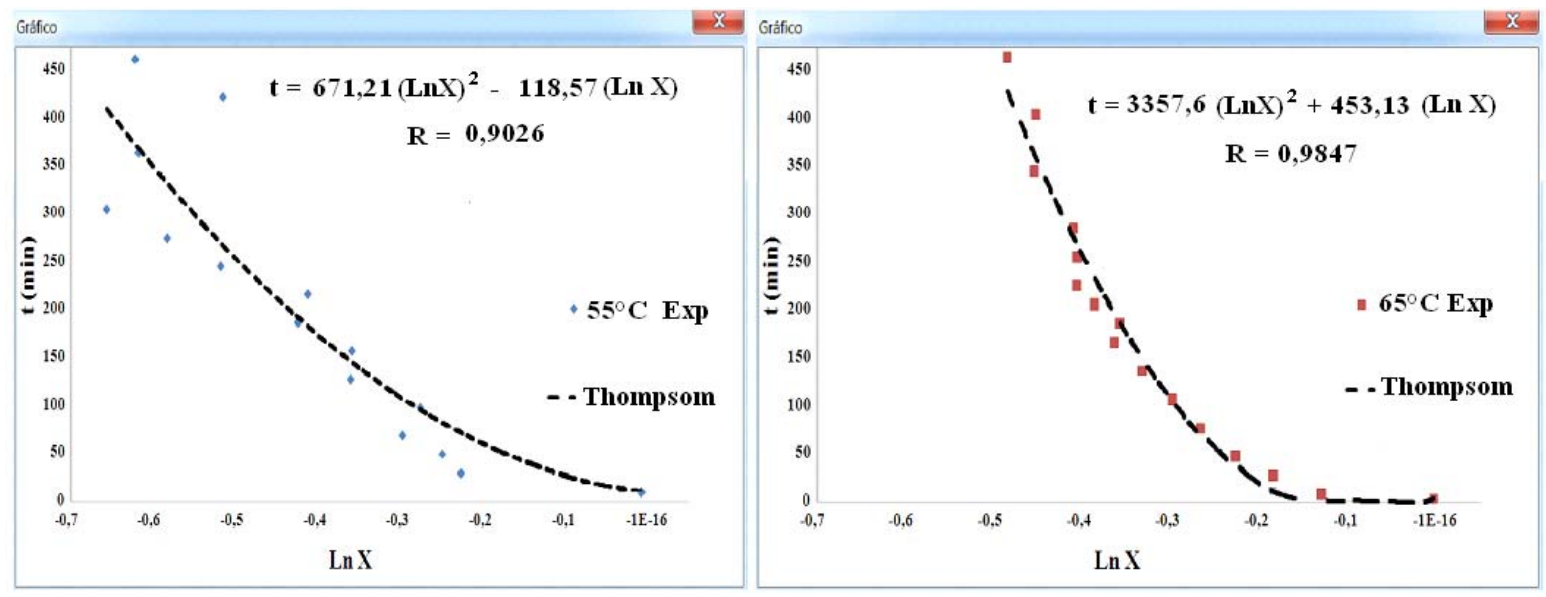

a)

b)

Figura 1. Simulação dos dados experimentais por Thompson et al. (1968). a) a $41^{\circ} \mathrm{C}$; b) a $45^{\circ} \mathrm{C}$. 

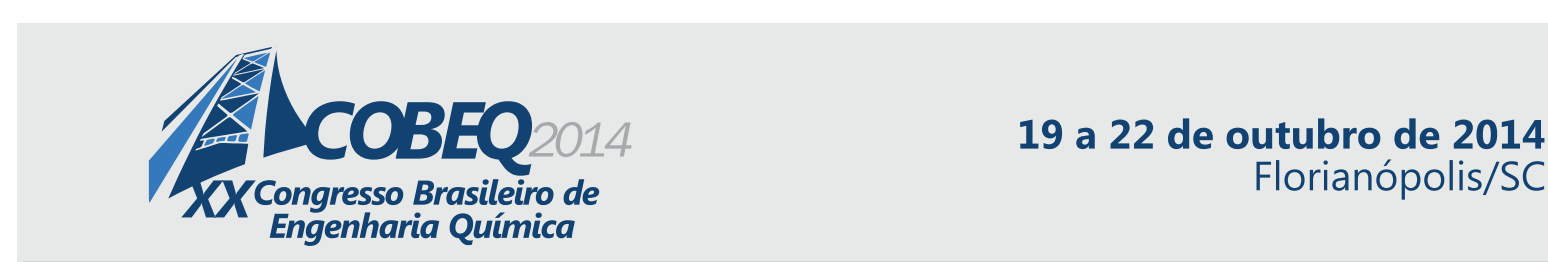

Florianópolis/SC
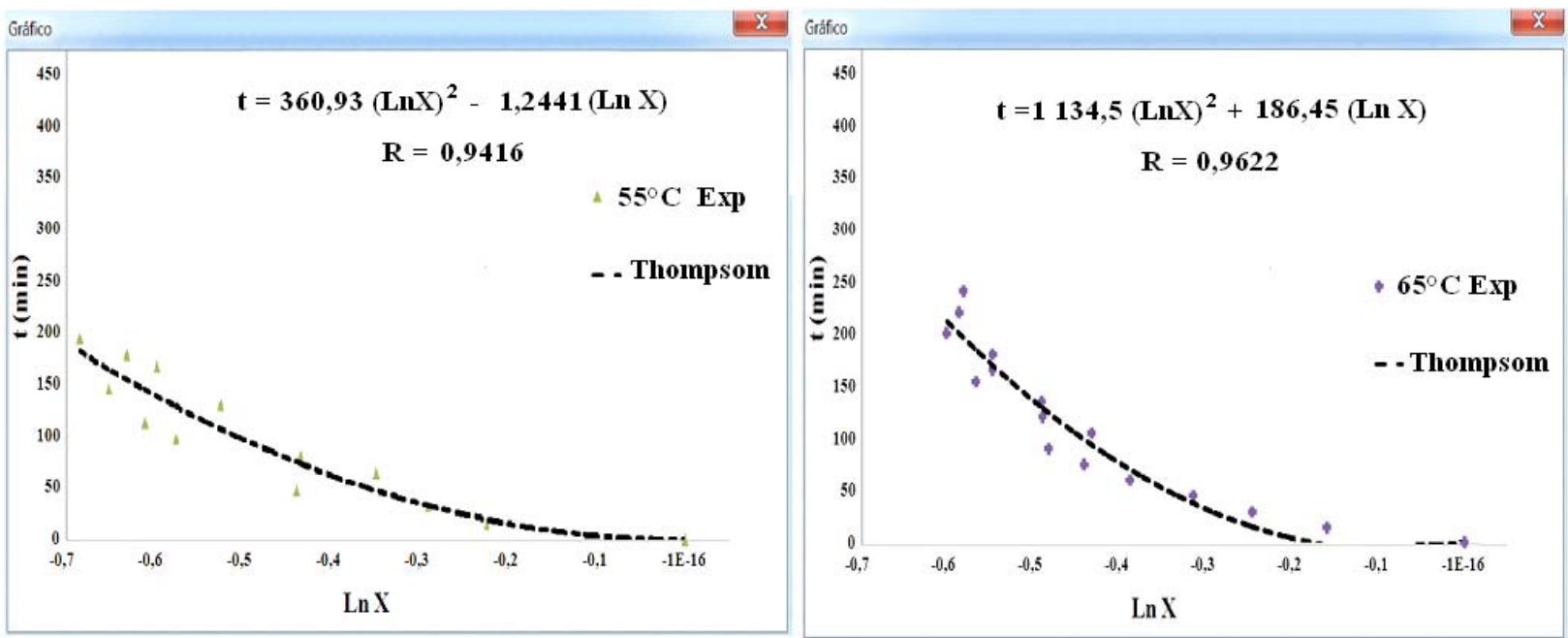

a)

b)

Figura 2. Simulação dos dados experimentais a por Thompson et al. (1968). a) $55^{\circ} \mathrm{C}$ e b) $65^{\circ} \mathrm{C}$.

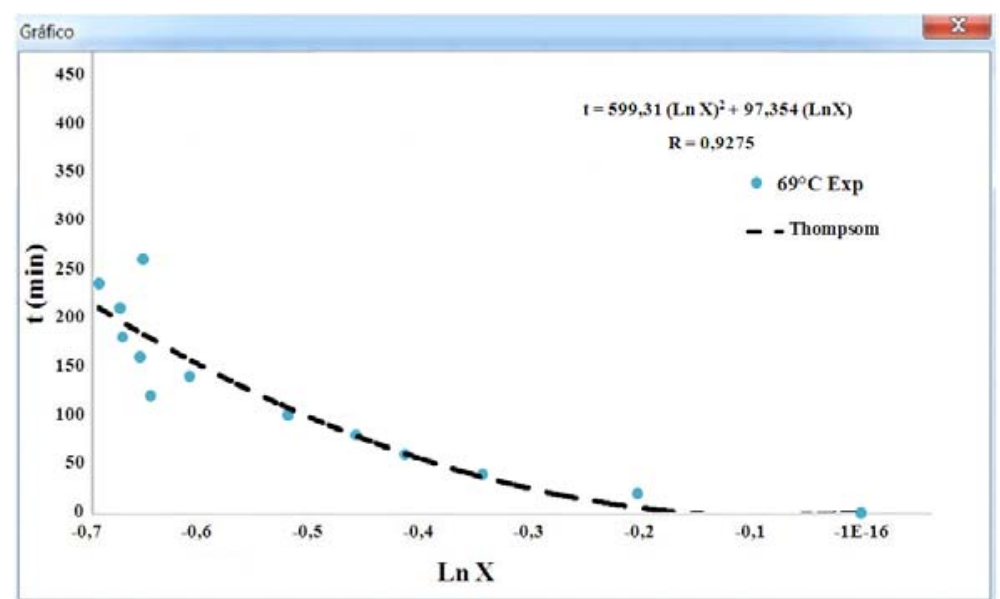

Figura 3. Simulação dos dados experimentais a $69^{\circ} \mathrm{C}$ por Thompson et al. (1968)

Como para a secagem com luz infravermelha este valor ficou entre 46\%, após 90 min de processo. O que demonstra que o processo de secagem usando a luz infravermelha é mais eficiente que o convencional, tanto na retirada de umidade quanto no tempo de secagem. Uma comparação entre os resultados obtidos neste trabalho com os da secagem convectiva mostrou que é possível obter o malte de milho seco pelo método da secagem com ondas infravermelhas, mantendo as qualidades obtidas em um secador convectivo, mas com um tempo de secagem de 3 a 4 vezes menor e retirando $7 \%$ a mais de umidade do que a secagem comum. E como um tempo maior de secagem requer maior consumo de energia e, conseqüentemente, maior gasto de recursos financeiros, a secagem com infravermelho apresenta uma vantagem econômica em relação à convencional. 
A Tabela 4 apresenta o custo relativo da produção de cerveja, no Brasil. A cevada é responsável por quase $15 \%$ dos custos individuais e como o seu custo no Brasil, devido a importação, alcança 240 US\$/t de sementes. Como o milho, por ser largamente produzido no Brasil, tem um preço de venda de 180 US\$/t de semente, a substituição do malte de cevada pelo malte de milho acarretaria numa redução de $77 \%$ dos custos com o malte e de $21 \%$ dos custos totais.

Tabela. 4. Composição dos custos das cervejas de malte de cevada e de milho.

\begin{tabular}{lcccccccccc}
\hline & \multicolumn{9}{c}{ Custos Variáveis (\%) } & \multicolumn{4}{c}{ Custos fixos (\%) } \\
& Malte & Maltose & Salários & Utilidades & Aditivos & Outros & Vendas & Administração & Depreciação & outros \\
\hline Cevada & 14,8 & 3,30 & 3,70 & 3,20 & 0,79 & 1,80 & 18,4 & 13,9 & 11,0 & 29,2 \\
Milho & 3,40 & 3,74 & 4,20 & 3,63 & 0,70 & 2,04 & 20,9 & 15,8 & 12,5 & 33,1 \\
\hline
\end{tabular}

A Figura 4 apresenta o resultado das análises sensoriais das cervejas obtidas com o malte de milho (cervejas A e C), comparadas com a duas cervejas comerciais (cervejas B e D). Desta figura, nota-se que a cerveja de malte de milho é tão boa quanto às cervejas de cevada (comerciais). O que deixaria as cervejas mais baratas e competitivas, sem reduzir a qualidade delas. O Fermento da Flashmann produziu uma cerveja tão boa quanto a melhor cerveja comercial, alcançando uma pontuação próxima ou maior do que 7 pontos na escala hedônica para o sabor, aroma e aparência.

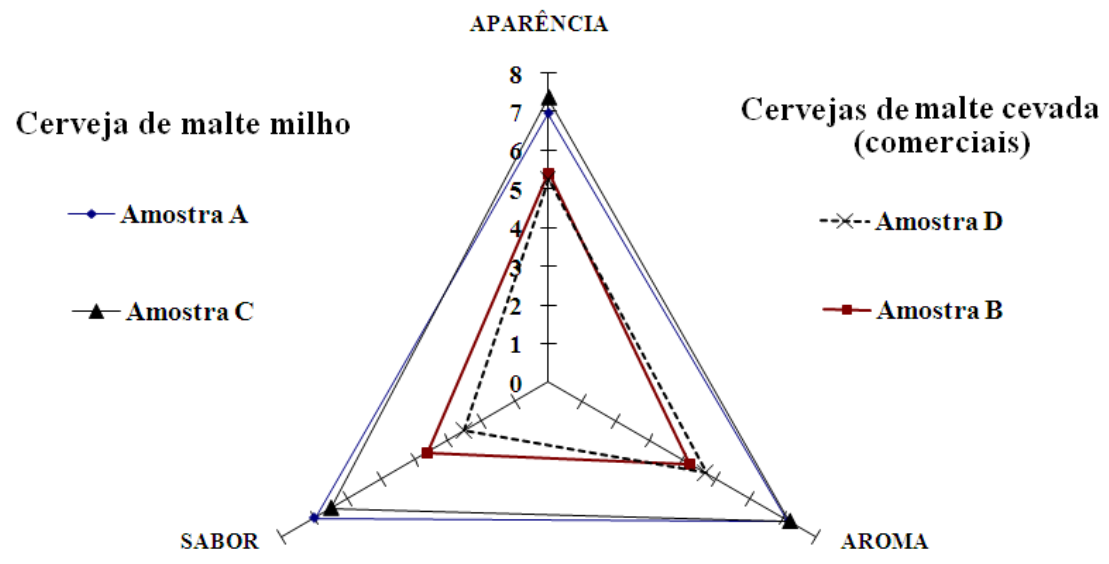

Figura 4. Resultados em escala hedônica para as análises sensoriais das cervejas.

\section{CONCLUSÕES}

Os resultados mostraram que a melhor condição para secar o malte de milho foi a $55{ }^{\circ} \mathrm{C}$ por 1,5h de processo, e este tempo foi de cerca de 4 vezes menor do que a secagem do malte de milho em um secador convectivo. Comparando a qualidade sensorial da cerveja de milho mostrou que ela foi tão boa como as cervejas comerciais, além do seu custo ser $10 \%$ menor, o que torna este processo viável e competitivo. 


\section{AGRADECIMENTOS}

Os autores agradecem a UNINOVE e a FAPESP pela bolsa e suporte financeiro à pesquisa.

\section{REFERÊNCIAS}

BIAZUS, J.P.M.; SOUZA, A.G.; SANTANA, J.C.C.; SOUZA, R.R.; TAMBOURGI, E.B. Optimization of drying process of Zea mays malt to use as alternative source of amylolytics enzymes. Braz. Arc. Bio. Technol. v.48, Special, p.185-190, 2005.

BIAZUS, J.P.M.; SOUZA, R.R.; CURVELO-SANTANA, J.C.; TAMBOURGI, E.B. Otimização da secagem do malte de Zea mays. Ciênc. Tecnol. Aliment. v.26, n.4, p.787-792, 2006.

CEYLAN, I. Determination of drying characteristics of timber by using artificial neural networks and mathematical models. Dry. Technol. v.26, n.12, p. 1469-1476, 2008.

FERNANDES, F.A.N.; RODRIGUES, S. Application of Ultrasound and Ultrasound-Assisted Osmotic Dehydration in Drying of Fruits. Dry. Technol. v.26, n.12, p. 1509 - 1516, 2008.

GUEDES, A.M.M.; FARIAS, L.J.G. Determinação da constante de secagem de urucum (Bixa orellana L.) em secador convectivo de leito fixo. Braz. J. Agroind. Prod. v.2, n.1, p.73-86, 2000.

LEWIS, W.K. The rate of drying of solids materials. Ind. Eng. Chem.. 5, p.427-432, 1921.

OMID, M.; BAHARLOOEI, A.; AHMADI, H. Modeling drying kinetics of pistachio nuts with multilayer feed-forward neural network. Dry. Technol. v.27, n.10, pp. 1069-1077, 2008.

PHOUNGCHANDANG, S.; TOCHIP, L.; SRIJESDARUK, V. White mulberry leaf drying by heat pump dehumidified dryers. J. Agri. Sci. v.4(Special), p. 844-851, 2008.

SANTANA, J.C.C.; ARAÚJO, S.A.; LIBRANTZ, A.F.H.; TAMBOURGI, E.B. Optimization of the corn malt drying by use of genetic algorithm. Dry. Technol. v.28,n.11,pp. 1236-1244, 2010.

THOMPSON, T.L.; PEART, R.M.; FORSTER, G.H. Mathematical simulation of corn drying A new model. Trans. ASAE. v.11, n.4, p. 582-586, 1968.

WANG, C.Y.; SINGH, R.P.A single layer drying equation for rough rice. Amer. Soc. Agric. Bio. Eng. paper nº78-3001, 1978. 